\title{
CXCR4 WHIM-Like Mutation
}

National Cancer Institute

\section{Source}

National Cancer Institute. CXCR4 WHIM-Like Mutation. NCI Thesaurus. Code C124130.

Somatic point mutations or frameshift mutations in the CXCR4 gene that result in the truncation of between 10 and 19 amino acid residues from the carboxyl terminus of C-XC chemokine receptor type 4 protein (CXCR-4) and are associated with Waldenstrom Macroglobulinemia. These mutations are similar to those found in the hereditary disease WHIM (warts, hypogammag lobulinemia, infections, and myelokathexis) syndrome and encode a constitutively active form of the CXCR-4 protein. 